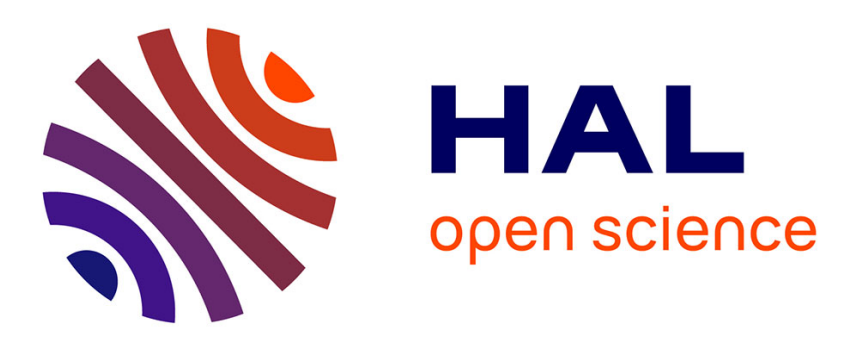

\title{
Impact of modified alumina oxides on the fire properties of PMMA and PS nanocomposites
}

Nicolas Cinausero, Nathalie Azema, José-Marie Lopez-Cuesta, Marianne Cochez, Michel Ferriol

\section{- To cite this version:}

Nicolas Cinausero, Nathalie Azema, José-Marie Lopez-Cuesta, Marianne Cochez, Michel Ferriol. Impact of modified alumina oxides on the fire properties of PMMA and PS nanocomposites. Polymers for Advanced Technologies, 2011, 22 (12), pp.1931-1939. 10.1002/pat.1695 . hal-02949487

\section{HAL Id: hal-02949487 \\ https://hal.science/hal-02949487}

Submitted on 1 Jun 2021

HAL is a multi-disciplinary open access archive for the deposit and dissemination of scientific research documents, whether they are published or not. The documents may come from teaching and research institutions in France or abroad, or from public or private research centers.
L'archive ouverte pluridisciplinaire HAL, est destinée au dépôt et à la diffusion de documents scientifiques de niveau recherche, publiés ou non, émanant des établissements d'enseignement et de recherche français ou étrangers, des laboratoires publics ou privés. 


\title{
Impact of modified alumina oxides on the fire properties of PMMA and PS nanocomposites
}

\author{
Nicolas Cinausero ${ }^{a * \dagger}$, Nathalie Azema ${ }^{a}$, José-Marie Lopez Cuesta ${ }^{a}$, \\ Marianne Cochez ${ }^{b}$ and Michel Ferriol ${ }^{b}$
}

\begin{abstract}
Grafting of ethylene glycol methacrylate phosphate (EGMP) monomer polymerized from alumina nanoparticles has been performed in order to confer a better thermal stability and fire retardancy to PMMA and PS nanocomposites. Grafting and polymerization processes have been investigated using FTIR, TGA, and elemental analyses. Thermal stability and decomposition routes of monomer and polymer grafted alumina have been studied using thermogravimetric analysis and compared with the thermal behavior of the same alumina modified with octylsilane. The thermal stability of EGMP supported by the nanoparticles is higher than that of free EGMP. The incorporation of 5 wt\% of both surface treated alumina in PMMA and PS leads to an improvement of thermal stability in comparison with unfilled polymers as well as nanocomposites containing unmodified alumina. Furthermore, the grafting of organic compounds on alumina also allows the peak of heat release rate measured using a cone calorimeter to be significantly reduced for PMMA nanocomposites.
\end{abstract}

Keywords: flame-retardancy; nanocomposites; surface modification; alumina

\section{INTRODUCTION}

It is now well known that the incorporation of nanoparticles in polymers allows a significant enhancement of a large range of their properties. Hence, fire retardancy is improved by selecting adequate nanoparticles as additives in flame-retardant compositions for a given polymer. Due to their large specific surface area, interfacial interactions of nanoparticles and host polymers as well as catalytic effects on thermal degradation reactions, able to modify the polymer degradation pathway, can produce positive effects on fire behavior. Moreover, the use of nanoparticles having a high aspect ratio can entail specific physical effects such as mass transfer limitations due to barrier effects.

Concerning the use of metal oxide nanoparticles, particularly investigated in PMMA, their influence has been attributed to the restriction of polymer chain mobility and to the high thermal diffusivity of the filler increasing the heat transfer inside the material. ${ }^{[1,2]}$ In the case of silica, hydrogen bonding interactions between carbonyl groups in PMMA and hydroxyl groups on silica surface have been put forward to account for the enhancement of behavior of PMMA-silica nanocomposites. ${ }^{[3]}$ Conversely, Hu et al. ${ }^{[4]}$ reported that the trapping effect of radicals released during polymer degradation by the silica particles was dominant as well as their role of gas barrier.

In the case of $\mathrm{Fe}_{2} \mathrm{O}_{3}$ and $\mathrm{TiO}_{2}$ nanoparticles, adsorption of polymer on the oxide surface via methoxycarbonyl groups was proposed to explain the thermal stabilization of PMMA. ${ }^{[5]}$ Nevertheless, in the case of $\mathrm{TiO}_{2}$ and for loadings higher than $5 \mathrm{wt} \%$, a catalytic effect on PMMA degradation was highlighted. ${ }^{[6]}$ It was explained by interactions between the methoxycarbonyl groups and the hydroxyl groups present on the oxide surface.

Since the use of surface treatments of metal oxide nanoparticles is a novel way to enhance functional properties of nanocomposites, it can be expected that adverse catalytic effects on their thermal degradation could be avoided. Moreover, the grafting of polymeric structures containing phosphorus compounds also suggests the possibility to improve the flame retardancy, due to the expected role of phosphorus on thermal degradation mechanisms involving the particle/polymer interface.

According to the literature several ways are available to produce metal oxides nanoparticles/polymer hybrids. Among them, the "grafting onto" method consists in the creation of physical or chemical interactions between polymer chains and inorganic surface. ${ }^{[7]}$ Conversely, in the "grafting from" method, the polymerization is carried out directly from oxide surface. ${ }^{[8]}$

In a previous study, ${ }^{[9]}$ we performed the grafting of alumina nanoparticles by phosphonic acid-based oligomers using the "grafting onto" method. Despite that thermal stability was improved, only a limited decrease of peak of heat release rate (HRR) was achieved.

* Correspondence to: N. Cinausero, Centre des Matériaux de Grande Diffusion, Ecole des Mines d'Alès, 6 avenue de Clavières, 30319 ALES Cedex, France. E-mail: nicolas.cinausero@insa-lyon.fr

a N. Cinausero, N. Azema, J. L. Cuesta

Centre des Matériaux de Grande Diffusion, Ecole des Mines d'Alès, 6 avenue de Clavières, 30319 ALES Cedex, France

b M. Cochez, M. Ferriol

Laboratoire MOPS, ex-UMR CNRS 7132, Département de Chimie de I'IUT de Moselle-Est, Université Paul Verlaine-Metz, 12 rue Victor Demange, 57500 Saint-Avold, France

Laboratoire des Matériaux Macromoléculaires/IMP, UMR 5627 - IMP, INSA Lyon, Bât. Jules Vernes, 20 avenue A. Einstein, 69621 Villeurbanne, France. 
<smiles>C=C(C)C(C)(C)C(=O)OCCOP(C)(=O)O</smiles>

Figure 1. Chemical structure of ethylene glycol methacrylate phosphate (EGMP).

The objectives of the present work are as follows:

- Grafting of another kind of phosphorus compound: ethylene glycol methacrylate phosphate (EGMP) monomer, which can be polymerized using the "grafting from" method on the same nanometric alumina.

- Study of the grafting process as well as investigation of the thermal stability of the above-modified alumina, in comparison with an unmodified one or an alumina modified using an organosilane.

- Study of the thermal behavior and fire retardancy of PMMA and PS modified alumina nanocomposites in order to determine the potential effectiveness of phosphorus present in the grafted EGMP polymer.

\section{EXPERIMENTAL}

\section{Materials}

Pellets of PMMA (Altuglas V 825T, Arkema) and PS (Total Petrochemicals, crystal PS 1960N) were reduced in powder before being blended with nanoparticles in an internal mixer. Commercial hydrophilic alumina, designated in the following by "Alu" (Aeroxide Alu C, Evonik Degussa), and hydrophobic alumina modified with octylsilane, designated by "Alu-C8" (Aeroxide Alu C 805, Evonik Degussa), were both $13 \mathrm{~nm}$ average diameter nanoparticles. Hydrophilic alumina was also treated with EGMP supplied by Sigma-Aldrich. Toluene and acetone were purchased from Prolabo (France). Free radical initiator, 2,2'-azobis(isobutyronitrile) (AIBN, Sigma-Aldrich), was first purified by recrystallization before polymerization.

\section{Encapsulation of modified nanoalumina by EGMP via free radical polymerization}

Prior to the grafting of EGMP (Fig. 1), to the hydroxyl groups of alumina via the $\mathrm{P}-\mathrm{OH}$ groups, pristine powders were dried at $100^{\circ} \mathrm{C}$ for $12 \mathrm{hr}$. The quantity of grafting agent EGMP required for the surface modification of pristine alumina was determined from the calculation of a monolayer coverage of EGMP molecules, based on a molecular surface area of $36 \AA^{2}$ (modelization with CS Chem3D software). EGMP molecules with $x=1$ were considered for calculations and discussions since it is the most representative form.

Thus, a threefold excess of the theoretical mass of $0.083 \mathrm{~g}$ of EGMP for $1 \mathrm{~g}$ Alu was used. That corresponds to an organic/ inorganic ratio of $0.248 \mathrm{~g} / \mathrm{g}$. Grafting and encapsulation were carried out in toluene from the proper amount of alumina required to make nanocomposites. Thus, $74 \mathrm{~g}$ of Alu were dispersed in $2.8 \mathrm{I}$ toluene and stirred during $5 \mathrm{~min}$. Meanwhile, $18.3 \mathrm{~g}$ of EGMP were dissolved in $200 \mathrm{ml}$ of toluene, and then added to the homogenized suspension of alumina. After stirring for $24 \mathrm{hr}$ at room temperature, $14.8 \mathrm{~g}$ of AIBN and a solution of $55.7 \mathrm{~g}$ of EGMP in $300 \mathrm{ml}$ of toluene were introduced into the reactor. Free radical copolymerization of additional EGMP with the methacrylate group of Alu-EGMP was performed at $80^{\circ} \mathrm{C}$ for $3 \mathrm{hr}$ (Fig. 2). Then, the washing step followed by the centrifugation was achieved successively with toluene and acetone. Finally, the solid phase (designated by "Alu-PMP," PMP corresponding to poly(ethylene glycol methacrylate phosphate) was dried successively at $100^{\circ} \mathrm{C}$ for $6 \mathrm{hr}$ and under vacuum at $100^{\circ} \mathrm{C}$ for $4 \mathrm{hr}$.

\section{Preparation of nanocomposites}

The test samples were prepared by mixing polymer powders (PS or PMMA pellets size reduced in a Pallman crushing machine) and alumina fillers (each formulation containing $5 \mathrm{wt} \%$ of inorganic filler) in a Haake PolyLab internal mixer at $225^{\circ} \mathrm{C}$ for PMMA $\left(200^{\circ} \mathrm{C}\right.$ for PS) and $50 \mathrm{rpm}$. The total mixing time was typically $8 \mathrm{~min}$. The resulting nanocomposites were crushed in Alpine rotary cutter mill before being compression molded at $225^{\circ} \mathrm{C}$ for $5 \mathrm{~min}$ at 100 bars to obtain $100 \mathrm{~mm} \times 100 \mathrm{~mm} \times 4 \mathrm{~mm}$ specimens for cone calorimeter measurements. The same procedure was applied to

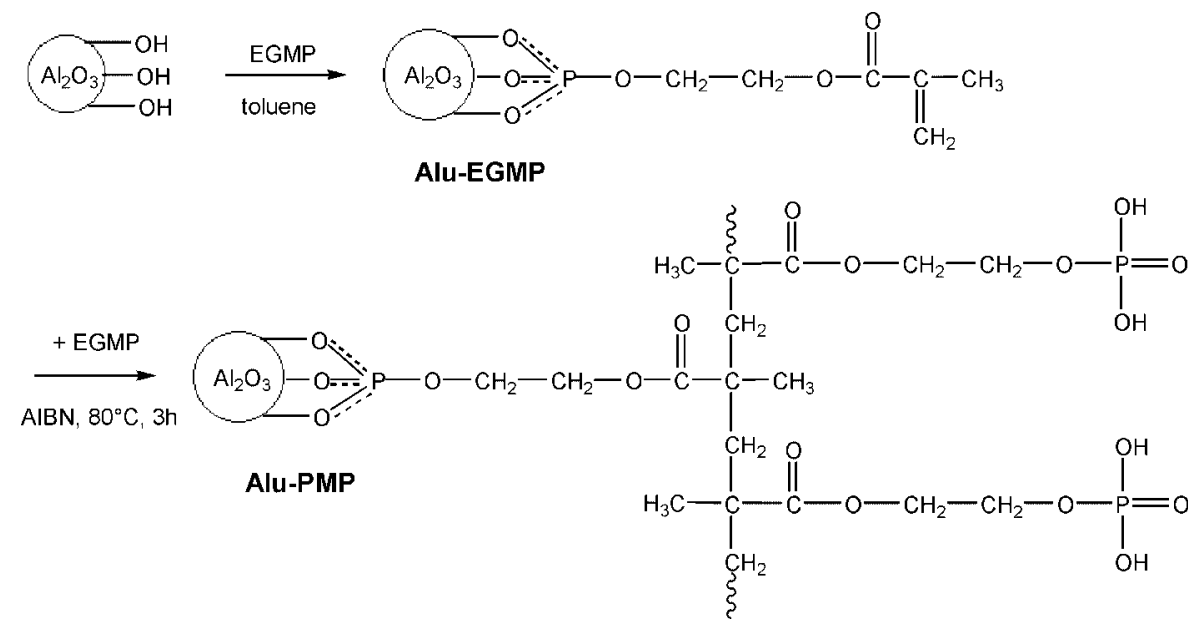

Figure 2. Scheme of the polymerization process of EGMP on Alu surface. 
pristine polymer in order to compare it properly with filled compositions.

\section{Instrumentation}

Thermogravimetric analyses (TGA) were performed with a Perkin Elmer Pyris 1 TGA thermobalance operating in air and with alumina crucibles containing around $10 \pm 2 \mathrm{mg}$ of material. The runs were carried out under dynamic conditions at the heating rate of $10^{\circ} \mathrm{C} / \mathrm{min}$ from room temperature to $700^{\circ} \mathrm{C}$.

ATR-FTIR spectra were recorded at room temperature on a Bruker IFS66 FTIR spectrometer (Golden Gate reflection system) to analyze the surface modification of nanometric alumina. The spectra were measured with a spectral resolution of $2 \mathrm{~cm}^{-1}$.

Images of nanocomposites were obtained with a scanning transmission electron microscopy (STEM) detector coupled with a SEM microscope (FEI Quanta 200 SEM). All images were obtained under high vacuum at a voltage of $25.0 \mathrm{kV}$ with a spot size of 2.8 and a working distance of $8.2 \mathrm{~mm}$. SEM-based X-ray microanalysis was used to obtain qualitative information about chemical composition of powders. A JEOL 1200 EX II was used to collect images of modified nanoparticles, obtained with a $100 \mathrm{kV}$ accelerating voltage.

Flammability tests were performed with the limited oxygen index (LOI) test, according to the ISO 4589 standard, using a Stanton Redcroft instrument on barrels $(80 \mathrm{~mm} \times 10 \mathrm{~mm} \times$ $4 \mathrm{~mm})$.

Evaluation of fire reaction of polymers and nanocomposites was made using a cone calorimeter device (Fire Testing Technology). Specimen sheets were exposed to a radiant cone under a heat flux of $35 \mathrm{~kW} / \mathrm{m}^{2}$. Time to ignition (TTI), total heat release (THR), peak of heat released rate (pHRR), gas release (CO/ $\mathrm{CO}_{2}$ ), smoke opacity, and amount of residue after burning will be discussed. Results correspond to mean values obtained from two or three experiments.

\section{RESULTS AND DISCUSSION}

\section{Characterization of EGMP modified alumina}

Thermal degradation of EGMP molecule was investigated by TGA before the grafting process (Fig. 3). EGMP follows a three-step decomposition. From 150 to $240^{\circ} \mathrm{C}$, EGMP would lose methacrylate groups ( $40 \mathrm{wt} \%$ mass loss of EGMP) with a maximum decomposition rate around $220^{\circ} \mathrm{C}$. Then, "ethylene glycol fragments" could be released on the $240-310^{\circ} \mathrm{C}$ temperature range ( $13 \mathrm{wt} \%$ mass loss) and finally, decomposition from 310 to $700^{\circ} \mathrm{C}$ may correspond to dehydration and condensation reactions of phosphate compounds ( $25 \mathrm{wt} \%$ ).

After grafting of EGMP onto alumina nanoparticles (designated by "Alu-EGMP") and polymerization step (designated by "Alu-PMP"), thermal degradation of these modified oxides was carried out by TGA (Fig. 4). For modified alumina Alu-EGMP, the maximum degradation rate appears at $261^{\circ} \mathrm{C}\left(+41^{\circ} \mathrm{C}\right.$ compared with EGMP), meaning that strong interactions between oxides and molecules could happen. Indeed, chemical adsorption between oxide surface and organophosphorus compounds are well known, as demonstrated by Guerrero et al. ${ }^{[10]}$ who modified metal oxide nanoparticles by grafting phenylphosphonic acid and its organic-soluble ester derivatives. These authors showed the formation of Al-O-P bonds leading to tridentate $\mathrm{PO}_{3}$ unit.

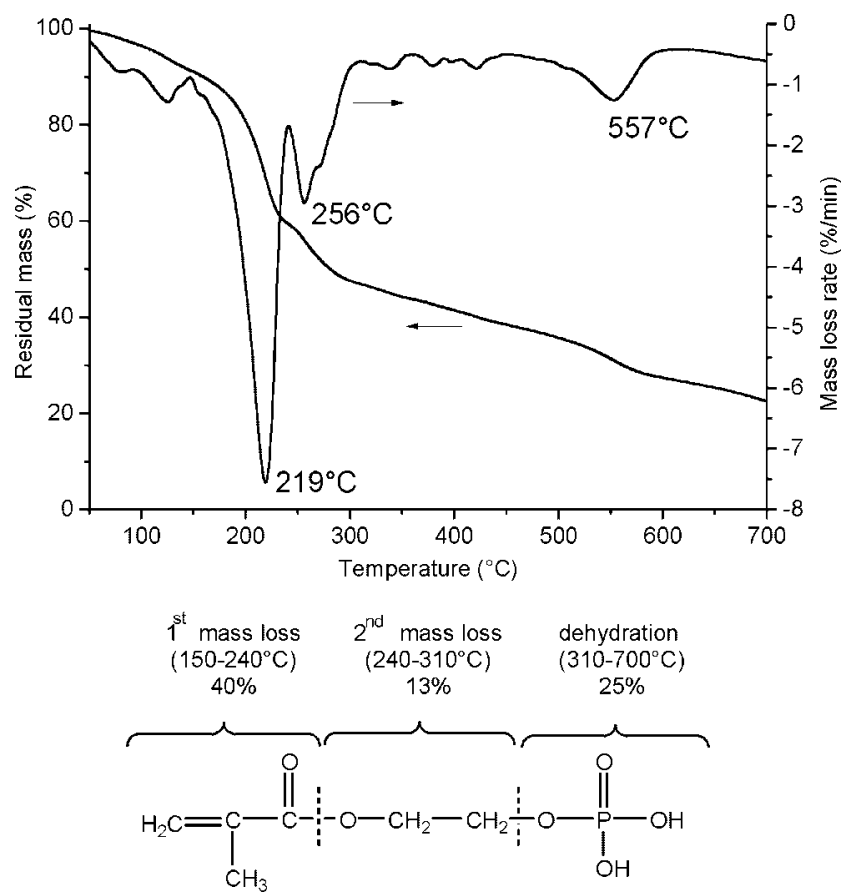

Figure 3. TGA and DTG curves under air of EGMP grafting agent.

The polymerization process led to the covering of oxide nanoparticles by a PMP network with a grafting ratio estimated at $36.2 \mathrm{wt} \%$ by TGA whereas the grafting ratio of Alu-EGMP was $10.2 \mathrm{wt} \%$ (Table 1). The thermal stability of Alu-PMP is much higher than for Alu-EGMP particles since the main decomposition step reaches its maximum at $347^{\circ} \mathrm{C}$. Thus, this strong thermal stability of hybrid particles allows high polymer processing temperatures without decomposition. Furthermore, the decrease of specific surface area of Alu-PMP from 86 to $63 \mathrm{~m}^{2} / \mathrm{g}$ is probably caused by the presence of the organic shell, increasing the particle size or leading to the partial aggregation of particles.

Figure 5 displays the FTIR spectra of EGMP grafting agent, pristine and modified alumina particles, whereas IR absorption bands are detailed in Table 2. A comparison of EGMP and Alu-EGMP spectra shows that most of the vibrations are similar: $\mathrm{CH}_{2}\left(2955 \mathrm{~cm}^{-1}\right), \mathrm{C}=\mathrm{O}\left(1718 \mathrm{~cm}^{-1}\right)$, vinylic groups $\left(1630 \mathrm{~cm}^{-1}\right)$, $(\mathrm{P}-) \mathrm{O}-\mathrm{C}$ at $1163 \mathrm{~cm}^{-1}$ revealing the presence of grafting agent

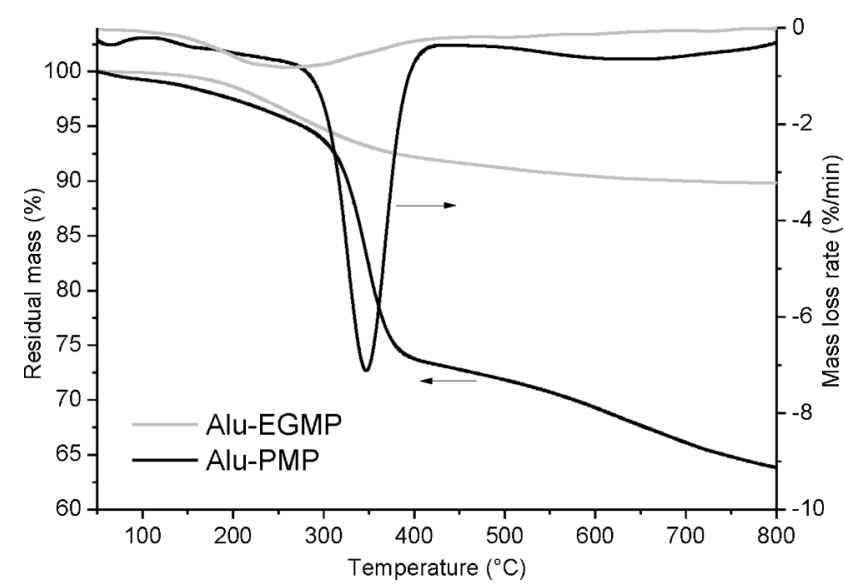

Figure 4. TGA and DTG curves of Alu-EGMP and Alu-PMP under air. 
Table 1. Thermal characteristics obtained by TGA under air, phosphorus amount, and specific surface area of nanoparticles

\begin{tabular}{|lcccc|} 
Powder & $T_{\mathrm{dm}}\left({ }^{\circ} \mathrm{C}\right)$ & Mass loss (\%) & $\mathrm{P}(\%)$ & $\mathrm{S}_{\mathrm{BET}}\left(\mathrm{m}^{2} / \mathrm{g}\right)$ \\
\hline Alu & - & 3 & - & 85.6 \\
Alu-EGMP & 261 & 10.2 & 2.18 & - \\
Alu-PMP & 347 & 36.2 & 8.13 & 63.5 \\
\hline
\end{tabular}
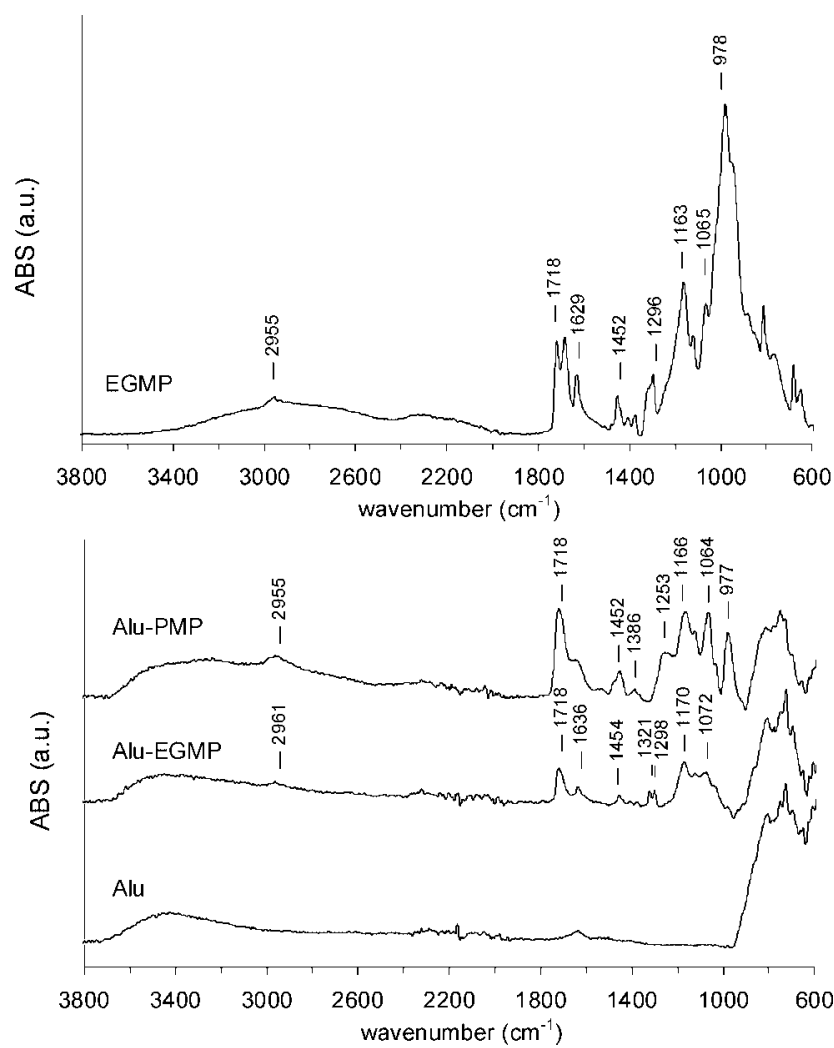

Figure 5. FTIR spectra of EGMP monomer and alumina nanoparticles.

on the surface of alumina. ${ }^{[11]}$ Furthermore, the chemical adsorption of EGMP on oxide is demonstrated by the disappearance of acid groups $\mathrm{P}(=\mathrm{O})-\mathrm{OH}\left(980 \mathrm{~cm}^{-1}\right)$. In addition, the absence of $\mathrm{P}=\mathrm{O}$ band at $1250 \mathrm{~cm}^{-1}$ may suppose the presence of tridentate $\mathrm{P}-(\mathrm{O}-\mathrm{Al})_{3}$ units. Alu-PMP spectrum contains, on the whole, the same bands as EGMP, but without bands at $1320-1300 \mathrm{~cm}^{-1}(\mathrm{C}(=\mathrm{O})-\mathrm{O}$ conjugated with $\mathrm{C}=\mathrm{C}$ in methacrylates) meaning that the radical polymerization occurred.

\section{Characterization of hydrophobic alumina}

Commercial powders Alu-C8 modified by octylsilane compounds were characterized mainly in order to understand their degradation pathway. The specific surface areas of $85.4 \mathrm{~m}^{2} / \mathrm{g}$ for Alu and $92.4 \mathrm{~m}^{2} / \mathrm{g}$ for Alu-C8 are not very different. TGA experiments (curves not shown) showed also that the decomposition of organosilane compounds begins at $300^{\circ} \mathrm{C}$ and is completed at around $600^{\circ} \mathrm{C}$ corresponding to a mass loss of $6.8 \mathrm{wt} \%$ at $700^{\circ} \mathrm{C}$.

The surface chemical composition of alumina Alu-C8 was investigated by X-ray microanalysis before and after thermal treatment. Thermal degradation of Alu-C8 at $350^{\circ} \mathrm{C}$ released carbon compounds and residual chlorine from chlorosilane vapor precursor, but silicon was still present on particles. In addition, complementary analyses by $\mathrm{Py} / \mathrm{GC} / \mathrm{MS}$ at $600^{\circ} \mathrm{C}$ of Alu-C8 particles exhibited exclusively the release of octane ( $m / z=114)$ during decomposition, without silicon-based compounds in vapor phase. This confirms the scission of $\mathrm{Si}-\mathrm{C}$ bond $\left(E_{\mathrm{d}}=306 \mathrm{~kJ} / \mathrm{mol}\right.$ whereas $\left.E_{\mathrm{d}}(\mathrm{C}-\mathrm{C})=331 \mathrm{~kJ} / \mathrm{mol}\right)$ of organosilanes and the presence of stable Al-O-Si structures. Thus, thermal treatment led to the formation of a "silica-like monolayer" $\mathrm{Si}-\mathrm{O}-\mathrm{Si}$ at the surface of the oxide particles covered by silanol groups after hydrolysis of the surface. These results are in agreement with the study of McElwee et al. ${ }^{[12]}$ who observed that during decomposition of $\mathrm{TiO}_{2}$ particles modified by organosilanes and organophosphorus compounds, quantities of $\mathrm{Si}$ and $\mathrm{P}$ elements are maintained after $400^{\circ} \mathrm{C}$. A chemical mechanism is proposed in Fig. 6.

\section{Sample morphology}

STEM pictures of PMMA and PS nanocomposites are given in Fig. 7. Pristine alumina is better dispersed in PMMA matrix than in PS due to the interactions between hydroxyl groups of oxide and polar groups of PMMA. However, hydrophobization of alumina does not lead to significant differences in terms of dispersion in PMMA whereas it is improved in PS compared with untreated alumina. This enhancement of Alu-C8 dispersion in PS is explained by better interactions between nanoparticles and polymer. The average size of Alu-PMP aggregates in both matrices is about $20-300 \mathrm{~nm}$ but a few micrometric agglomerates are also observed.

Table 2. IR absorption of the observed bands

\begin{tabular}{|lcccc|}
\hline Bond & Vibration & $\mathrm{cm}^{-1}$ & Bond & Vibration $^{-1}$ \\
\hline $\mathrm{O}-\mathrm{H}$ bonded & Stretching & $3500-3200$ & $\mathrm{P}=\mathrm{O}$ & Stretching \\
$\mathrm{CH}_{2}$ & Stretching & $2970-2950$ & $\mathrm{C}-\mathrm{O}$ & Stretching \\
$\mathrm{C}=\mathrm{O}$ & Stretching & 1720 & $(\mathrm{P}-) \mathrm{O}-\mathrm{C}$ & Stretching \\
$\mathrm{C}=\mathrm{C}$ & Stretching & $1640-1630$ & $\mathrm{P}(=\mathrm{O})-\mathrm{OH}$ & Stretching \\
$\mathrm{CH}_{2}$ & Deformation & $1460-1450$ & $\mathrm{P}-\mathrm{O}-\mathrm{C}$ & Stretching \\
$\mathrm{CH} 3$ & Deformation & $1410-1370$ & $\mathrm{Al}-\mathrm{O}$ & Stretching \\
$\mathrm{C}(=\mathrm{O})-\mathrm{O}^{*}$ & Stretching & 1320,1296 & & $980-970$ \\
$*$ Conjugated with $\mathrm{C}=\mathrm{C}$ in methacrylates. & & & $900-550$ \\
\end{tabular}




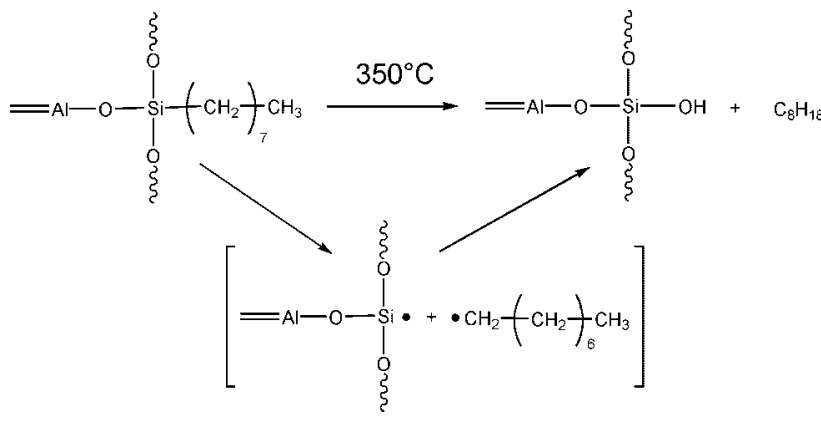

Figure 6. Schematic decomposition of organic monolayers of Alu-C8 nanoparticles.

\section{Thermo-oxidative degradation}

PMMA nanocomposites

Figure 8 highlights the positive effect of aluminum oxide nanoparticles on the thermal stability of PMMA. Values between brackets in Table 3 are the differences between characteristic temperatures of modified particles and those of Alu-containing compositions. These data give direct information on the stabilization or destabilization effect of the surface modification. The incorporation of $5 \mathrm{wt} \%$ of Alu leads to an increase of the initial degradation temperature $\left(T_{2 \%}\right)$ of PMMA nanocomposites of $26^{\circ} \mathrm{C}$. Indeed, metal oxides are known to annihilate early chain scissions caused by gas-phase oxygen effects. ${ }^{[9]}$ In $300-335^{\circ} \mathrm{C}$ temperature range, hydrophobic particles Alu-C8 cause a slight acceleration of the thermal degradation of PMMA compared to PMMA Alu 5\% nanocomposite, owing to the decomposition of the organic part of particles. This latter decomposition, implying scissions of $\mathrm{Si}-\mathrm{C}$ bonds of organosilanes coupling agents $\left(300-350^{\circ} \mathrm{C}\right)$, may promote further stabilization reactions, such as radical recombinations, which could occur to slow down the depolymerization process in the $335-365^{\circ} \mathrm{C}$ temperature range. These secondary reactions may be represented by the shoulder centered at $345^{\circ} \mathrm{C}$ on the DTG curves of PMMA Alu-C8 5\% composition in Fig. 8. At higher temperatures, thermal stability of
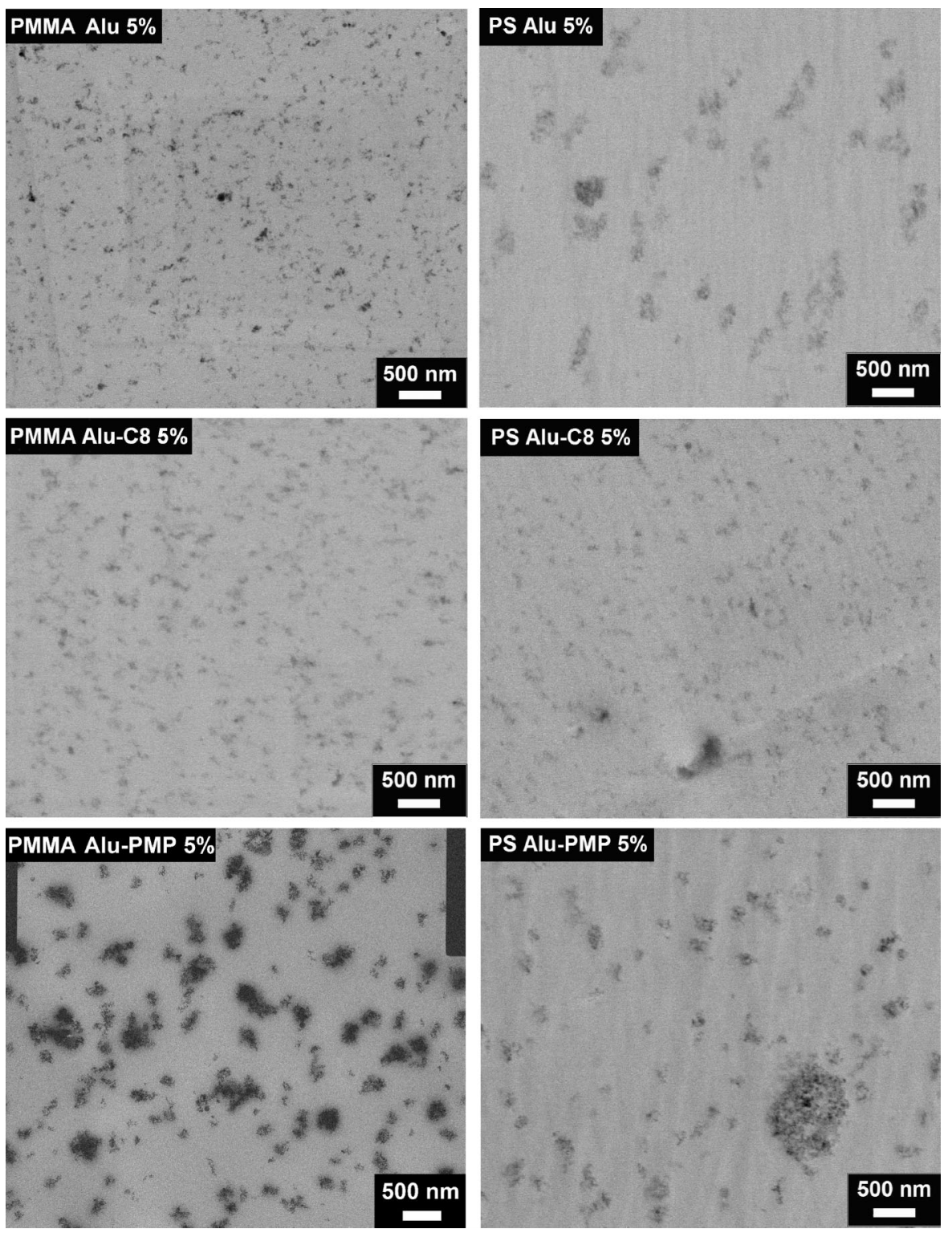

Figure 7. STEM images of PMMA and PS nanocomposites with $5 \mathrm{wt} \%$ inorganic fraction. 

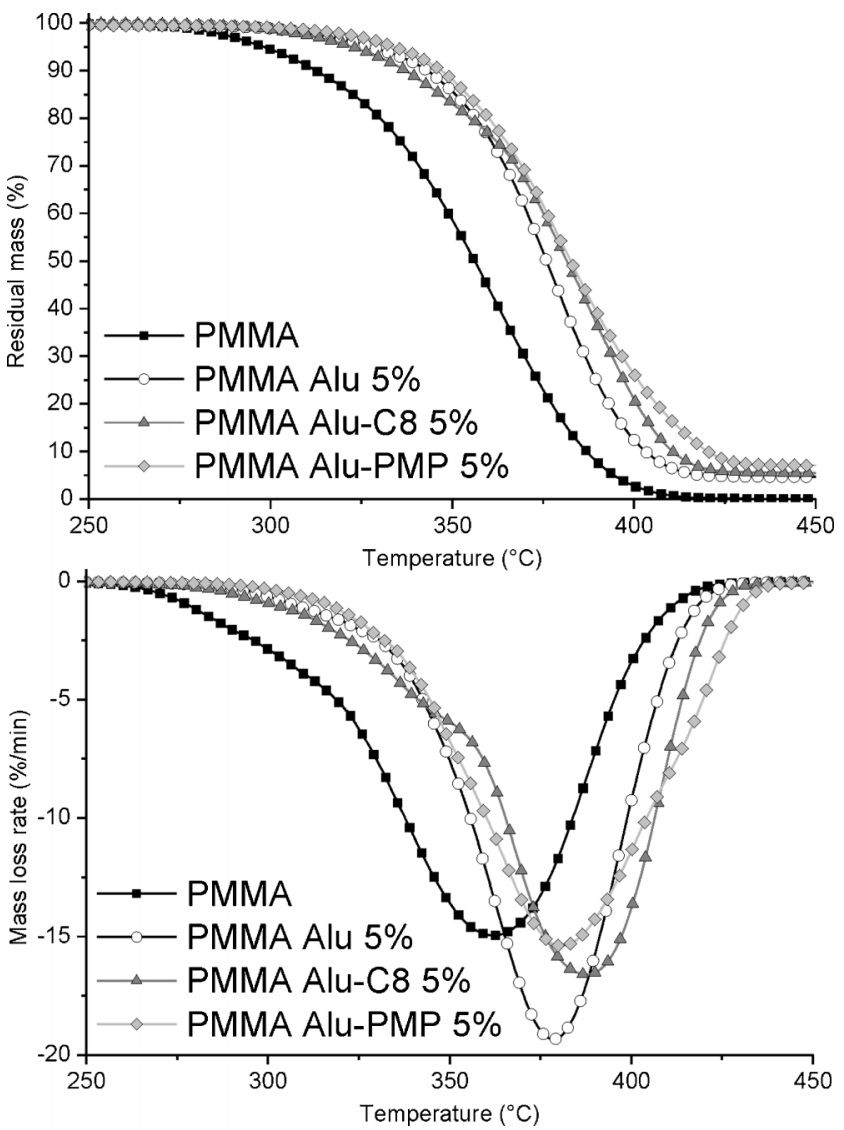

Figure 8. TGA and DTG curves under air for PMMA nanocomposites.

PMMA Alu-C8 5\% is enhanced compared with PMMA Alu 5\%. Besides, Alu-PMP nanoparticles stabilize the thermal degradation of PMMA on the whole range of temperature. This stabilization effect could be linked to reactions, between decomposition products of Alu-PMP particles $\left(T_{\mathrm{dm}}=347^{\circ} \mathrm{C}\right)$ and those of PMMA $\left(T_{\mathrm{dm}}=362^{\circ} \mathrm{C}\right)$ within the interphase region of composites. Indeed, a proper overlapping of thermal decomposition range of both polymer and flame retardants are often required to maximize the effect of additives on both thermal and fire properties. Besides, additional trapping effects of radicals by phosphorus compounds or specific interactions restricting the chain mobility may be other causes of the thermal stabilization of

Table 3. Degradation temperatures at $2 \%$ weight loss, at maximum rate of decomposition, and at $90 \%$ weight loss, of PMMA and PS nanocomposites from TGA experiments

\begin{tabular}{lccc|} 
Compositions & $T_{2 \%}$ & $T_{\mathrm{dm}}$ & $T_{90 \%}$ \\
\hline PMMA & 284 & 362 & 387 \\
PMMA Alu 5\% & 310 & 379 & 403 \\
PMMA Alu-C8 5\% & $305(-5)$ & $387(+8)$ & $411(+8)$ \\
PMMA Alu-PMP 5\% & $317(+7)$ & $381(+2)$ & $420(+17)$ \\
PS & 322 & 405 & 417 \\
PS Alu 5\% & 360 & 422 & 450 \\
PS Alu-C8 5\% & $353(-7)$ & $436(+14)$ & $458(+8)$ \\
PS Alu-PMP 5\% & $325(-35)$ & $441(+19)$ & $459(+9)$ \\
\hline
\end{tabular}

PMMA. ${ }^{[4,6,13]}$ The presence of phosphorus compounds may affect also degradation pathway of PMMA as it was demonstrated by studies about copolymerization of methyl methacrylate with a variety of comonomers with covalently bound phosphoruscontaining group. ${ }^{[14,15]}$ Pyrolysis of copolymers induced crosslinked structures from possible transesterifications of PMMA with phosphate group followed by the condensation of methacrylic anhydride units. A similar mechanism could explain the increase of stability in the presence of phosphorus compared to unmodified alumina, since phosphates are liable to form after decomposition of Alu-PMP. The improvement of $T_{90 \%}$ of PMMA Alu-PMP $5 \%$ of $17^{\circ} \mathrm{C}$ corresponds to the formation and to the stability of a carbonaceous char.

\section{PS nanocomposites}

Figure 9 shows the TGA and DTG curves of PS nanocomposites between 250 and $500^{\circ} \mathrm{C}$ under air atmosphere. Pristine alumina nanoparticles may act in the same way as for PMMA, concerning the limitation of oxygen effect on decomposition of PS. ${ }^{[16]}$ Indeed, the initial degradation temperature $\left(T_{2}\right)$ of PS Alu $5 \%$ is improved of $38^{\circ} \mathrm{C}$ compared to unfilled PS (Table 3). Other physicochemical processes are suggested like modification of the degradation pathway induced by metal oxide, adsorption of polymer fragments on oxide, and promotion of a protective barrier. ${ }^{[17,18]}$ The surface modification of nanoparticles leads to an acceleration of the thermal degradation of PS nanocomposites at low temperature compared with PS Alu 5\%. The phenomenon is more pronounced when using Alu-PMP particles since the
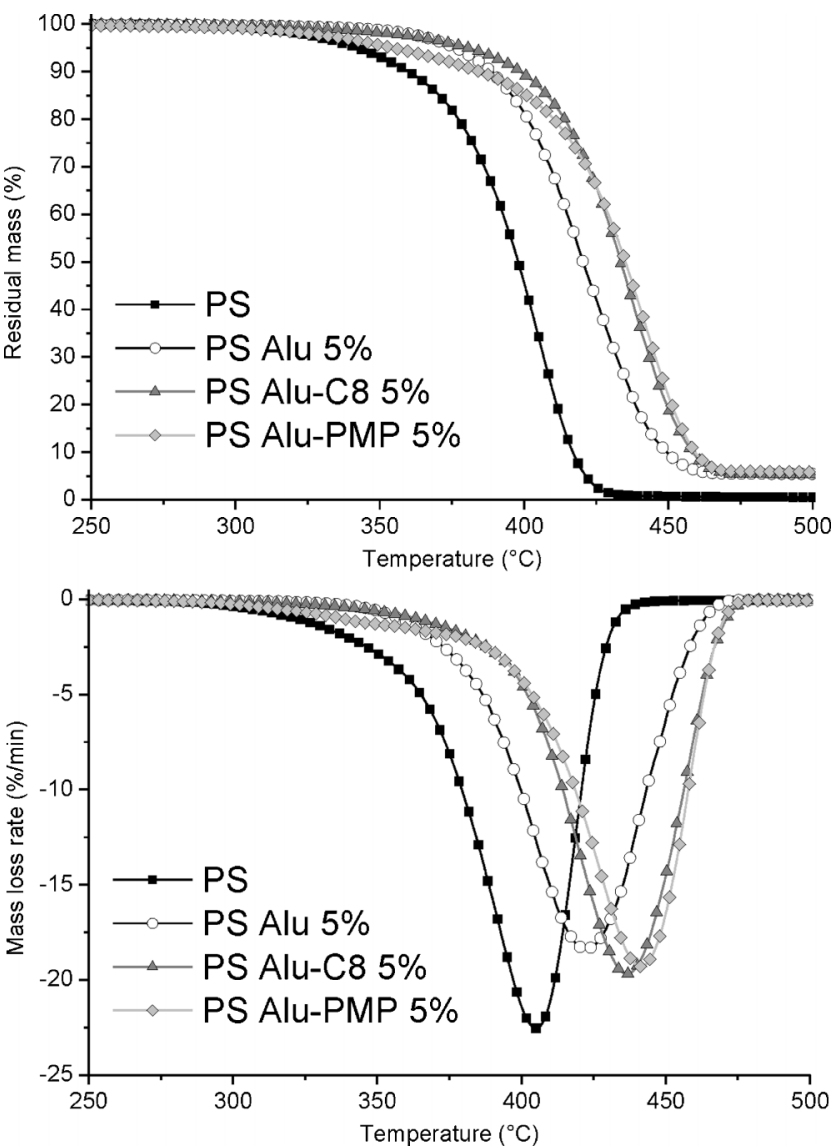

Figure 9. TGA and DTG curves under air for PS nanocomposites. 


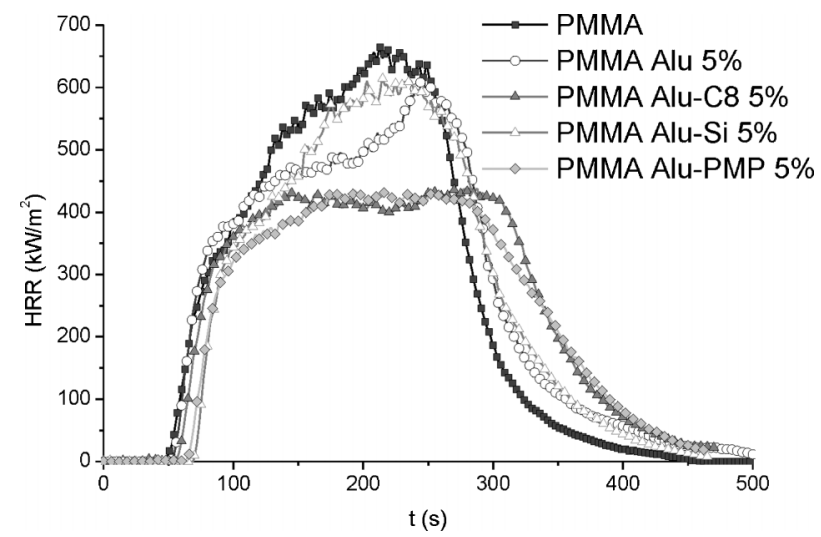

Figure 10. HRR curves of PMMA and its nanocomposites with $5 \mathrm{wt} \%$ inorganic fraction.

organic shell, which represents more than $25 \mathrm{wt} \%$ of hybrid particle, decomposes from $300^{\circ} \mathrm{C}$. Therefore, $T_{2} \%$ of PS Alu-PMP $5 \%$ nanocomposites is roughly equivalent to pure PS $\left(325^{\circ} \mathrm{C}\right)$. However, even if the loss of volatiles is accelerated in the first steps of degradation, $T_{\mathrm{dm}}$ of nanocomposites are then increased of, respectively, 14 and $19^{\circ} \mathrm{C}$ when incorporating Alu-C8 and Alu-PMP modified nanoparticles. The higher level of dispersion of Alu-C8 in PS matrix compared with untreated alumina may be a parameter to account for the improvement of the thermal stability. This cause is excluded in the case of Alu-PMP filled composition since the dispersion is not clearly improved with the surface modification. But in both cases, compounds resulting from the decomposition of organic shell may interfere with those of polymer. Surface modification of alumina may intensify secondary reactions like cyclization, dehydrogenation, scissions, $\mathrm{H}$-abstraction occurring during PS degradation. ${ }^{[19]}$ Thus, the products remain longer in the condensed phase and their release is delayed in temperature. ${ }^{[20]}$

\section{Fire reaction}

PMMA nanocomposites

Fire reaction of nanocomposites was investigated by cone calorimeter. The HRR curves of PMMA and nanocomposites are shown in Fig. 10. All corresponding data of calorimetry as well as LOI values are presented in Table 4. The incorporation of PMMA Alu $5 \%$ leads to a slight decrease of HRR between 120 and $240 \mathrm{sec}$ compared with pure PMMA. The accumulation of alumina particles toward the surface during combustion may explain this behavior. Nevertheless, pHRR is not notably decreased owing to the lack of cohesion of mineral particles agglomerated in "islands" (Fig. 11). Catalysis mechanisms can also modify the degradation pathway of filled PMMA since charred residues are formed around the oxide particles. Regarding Alu-C8 and Alu-PMP filled compositions, pHRR was drastically decreased by more than $30 \%$ in both cases in relation to unfilled PMMA. Furthermore, LOI increased to 19 for PMMA Alu-C8 5\% and 19.5 for PMMA Alu-PMP 5\% composition. The enhancement of fire properties can be firstly explained by the promotion of $a$ protective layer resulting from the covering of whole surface of sample by oxide nanoparticles. The formation of that protective barrier, limiting both external heat flux and mass transfers, is completed rapidly after ignition. Indeed, this could correspond to the stabilization of HRR, observed only $90 \mathrm{sec}$ after the ignition of material.

However, physical processes related to the fire behavior of nanocomposites are also coupled with chemical processes. In particular, surface treatment by octylsilane led to catalytic charring reactions and to the dispersion of particles during combustion probably caused by the decomposition of their organic shell. In order to highlight the effect of the decomposition step of Alu-C8, nanocomposites containing "Alu-Si" nanoparticles (Alu-C8 after thermal treatment at $350^{\circ} \mathrm{C}$, Fig. 6) were also tested in cone calorimeter. The HRR curve of such a composition was closely similar to unfilled polymer. Thus,

Table 4. Cone calorimeter data of PMMA compositions

\begin{tabular}{|c|c|c|c|c|c|c|c|c|c|}
\hline & $\begin{array}{l}\text { TTI } \\
\text { (sec) }\end{array}$ & $\begin{array}{c}\text { THR } \\
\left(\mathrm{MJ} / \mathrm{m}^{2}\right)\end{array}$ & $\begin{array}{c}\text { TSR } \\
\left(\mathrm{m}^{2} / \mathrm{m}^{2}\right)\end{array}$ & $\begin{array}{c}\text { pHRR } \\
\left(\mathrm{kW} / \mathrm{m}^{2}\right)\end{array}$ & $\begin{array}{l}\text { Residue } \\
\text { (\%) }\end{array}$ & $\begin{array}{c}\mathrm{CO} / \mathrm{CO}_{2} \\
\left(10^{3}\right)\end{array}$ & $\begin{array}{c}\mathrm{CO} \\
\left(10^{3} \mathrm{~kg} / \mathrm{kg}\right)\end{array}$ & $\begin{array}{c}\mathrm{CO}_{2} \\
(\mathrm{~kg} / \mathrm{kg})\end{array}$ & LOI \\
\hline PMMA & $59 \pm 2$ & $126 \pm 2$ & $479 \pm 44$ & $639 \pm 7$ & - & 3.3 & $6.8 \pm 0.4$ & $2.06 \pm 0.02$ & 18.0 \\
\hline PMMA Alu 5\% & $57 \pm 1$ & $124 \pm 1$ & $456 \pm 39$ & $601 \pm 15$ & $5.0 \pm 0.5$ & 3.5 & $7.2 \pm 0.0$ & $2.06 \pm 0.01$ & 18.5 \\
\hline PMMA Alu-C8 5\% & $56 \pm 2$ & $119 \pm 2$ & $482 \pm 57$ & $447 \pm 9$ & $5.8 \pm 0.4$ & 3.7 & $7.5 \pm 0.1$ & $2.03 \pm 0.02$ & 19.0 \\
\hline PMMA Alu-Si 5\% & $75 \pm 10$ & $122 \pm 0$ & $654 \pm 35$ & $613 \pm 2$ & $4.3 \pm 0.3$ & 4.3 & $8.8 \pm 0.7$ & $2.04 \pm 0.00$ & - \\
\hline PMMA Alu-PMP 5\% & $65 \pm 0$ & $113 \pm 1$ & $631 \pm 23$ & $440 \pm 5$ & $6.9 \pm 0.3$ & 6.6 & $12.6 \pm 0.5$ & $1.92 \pm 0.02$ & 19.5 \\
\hline
\end{tabular}
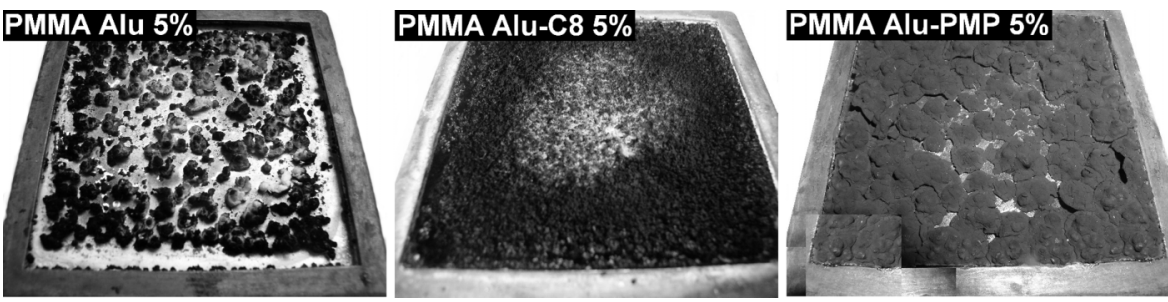

Figure 11. Photographs of char residues after cone calorimeter experiments of PMMA samples. 


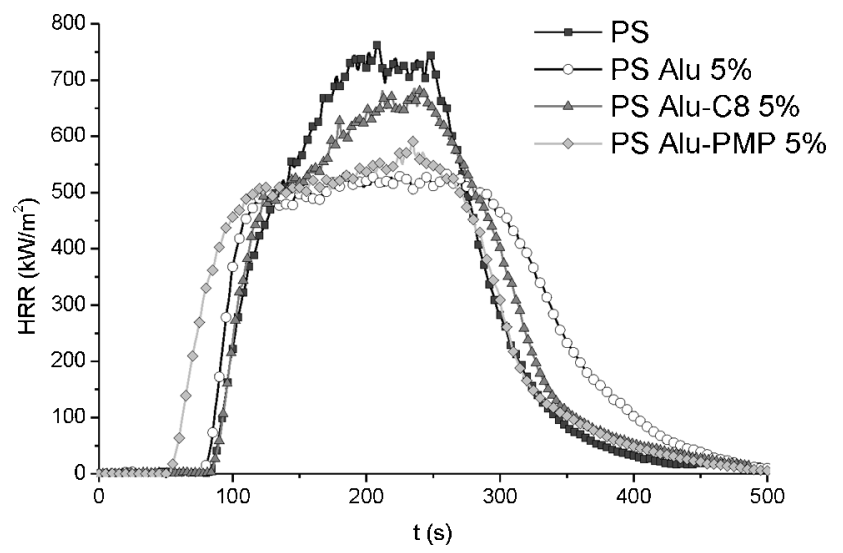

Figure 12. HRR curves of PS and its nanocomposites with $5 \mathrm{wt} \%$ inorganic fraction.

chemical interactions are likely to happen during decomposition processes of modified Alu-C8 between radicals induced by Alu-C8 degradation and decomposition products of PMMA. In addition, it was observed that TTI was delayed of $19 \mathrm{sec}$ using Alu-Si compared to Alu-C8, what would mean that $\mathrm{Si}-\mathrm{OH}$ groups (surface of Alu-Si) contribute to postpone the ignition.

As regards Alu-PMP effects on fire reaction of PMMA, further flame-retardant properties are interesting in addition to the decrease of pHRR: TTI is delayed of $6 \mathrm{sec}$ and THR decreases to $113 \mathrm{MJ} / \mathrm{m}^{2}$. This lower value of THR compared to PMMA means that fireload is less important, in other words, less organic material is converted into combustible gases to feed the fire. This phenomenon can be ascribed mainly by char promotion in view of the mass of residue (6.9 wt\%). Indeed, phosphorus groups could act in solid phase by forming an efficient and thermally stable protective barrier resulting from the condensation of phosphate groups. Nevertheless, actions in the gas phase of phosphorous compounds by trapping radicals are not excluded. Despite these positive aspects of flame retardancy, smoke production is more intense, promoted by incomplete combustion of materials, typically characterized by an increase of $\mathrm{CO} / \mathrm{CO}_{2}$ ratio.

\section{PS nanocomposites}

Cone calorimeter curves of PS nanocomposites are presented in Fig. 12 and the experimental data in Table 5. The incorporation of $5 \mathrm{wt} \%$ Alu leads to a decrease of peak of HRR from 752 to $547 \mathrm{~kW} /$ $\mathrm{m}^{2}(-27 \%)$, whereas no enhancement of LOI is noted. The other cone calorimeter data are rather stable compared to pure PS (TTI, THR, smoke opacity, $\left.\mathrm{CO} / \mathrm{CO}_{2}\right)$. Thus, with pristine alumina, HRR is controlled by the presence of an inorganic barrier which limits gas transfers. Indeed, the residue of PMMA Alu 5\% exhibits a homogeneous structure covering the whole sample area (Fig. 13).

The surface modification does not imply an additional improvement of fire properties unlike PMMA nanocomposites. On the contrary, the presence of Alu-C8 leads to an antagonistic effect with a pHRR as high as $687 \mathrm{~kW} / \mathrm{m}^{2}(-9 \%)$. The residue does not exhibit any homogeneity with agglomerated particles covering partially the sample area. PS Alu-PMP 5\% composition features the same behavior as PS Alu $5 \%$ in terms of HRR. However, the ignition occurs at a shorter time due to the fast release of combustible gas ascribed to the weak stability of composite interphase, which is in accordance with the results of thermal degradation. In other words, for nonmodified alumina, the presence of hydroxyl groups $\mathrm{Al}-\mathrm{OH}$ leads to the highest level of flame retardancy as regards TTI and pHRR.

\section{CONCLUSION}

Grafting and polymerization of EGMP monomer on alumina nanoparticles have been performed in order to confer a better

Table 5. Cone calorimeter data of PS compositions

\begin{tabular}{|c|c|c|c|c|c|c|c|c|c|}
\hline & $\begin{array}{c}\text { TTI } \\
\text { (sec) }\end{array}$ & $\begin{array}{c}\text { THR } \\
\left(\mathrm{MJ} / \mathrm{m}^{2}\right)\end{array}$ & $\begin{array}{c}\text { TSR } \\
\left(\mathrm{m}^{2} / \mathrm{m}^{2}\right)\end{array}$ & $\begin{array}{c}\mathrm{pHRR} \\
\left(\mathrm{kW} / \mathrm{m}^{2}\right)\end{array}$ & $\begin{array}{c}\text { Residue } \\
(\%)\end{array}$ & $\begin{array}{c}\mathrm{CO} / \mathrm{CO}_{2} \\
\left(10^{3}\right)\end{array}$ & $\begin{array}{c}\mathrm{CO} \\
\left(10^{3} \mathrm{~kg} / \mathrm{kg}\right)\end{array}$ & $\begin{array}{c}\mathrm{CO}_{2} \\
(\mathrm{~kg} / \mathrm{kg})\end{array}$ & LOI \\
\hline PS & $83 \pm 0$ & $131 \pm 0$ & $5163 \pm 1$ & $752 \pm 10$ & $3.1 \pm 0.9$ & 29.3 & $67.1 \pm 1.4$ & $2.29 \pm 0.03$ & 18.5 \\
\hline PS Alu 5\% & $79 \pm 5$ & $132 \pm 2$ & $5222 \pm 69$ & $547 \pm 14$ & $4.0 \pm 0.8$ & 27.5 & $61.8 \pm 0.8$ & $2.25 \pm 0.01$ & 18.5 \\
\hline PS Alu-C8 5\% & $85 \pm 1$ & $128 \pm 1$ & $5117 \pm 98$ & $687 \pm 1$ & $4.7 \pm 0.6$ & 29.5 & $66.3 \pm 1.9$ & $2.25 \pm 0.03$ & 18.5 \\
\hline PS Alu-PMP 5\% & $55 \pm 1$ & $133 \pm 1$ & $4994 \pm 92$ & $592 \pm 3$ & $5.8 \pm 0.4$ & 27.5 & $64.6 \pm 0.3$ & $2.26 \pm 0.03$ & 19.0 \\
\hline
\end{tabular}
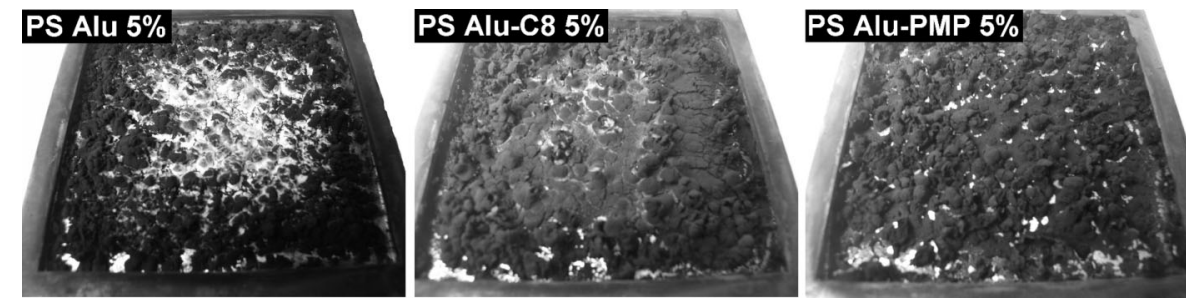

Figure 13. Photographs of char residues after cone calorimeter experiments of PS samples. 
thermal stability and fire retardancy to PMMA and PS nanocomposites. Thermal stability and decomposition routes of phosphorus monomer, polymer grafted alumina, and octylsilane modified alumina have been studied using TGA. Due to strong interactions between EGMP and alumina surface, the thermal stability of the monomer supported by the nanoparticles is higher than that of free EGMP. The incorporation of $5 \mathrm{wt} \%$ of surface treated alumina in both PMMA and PS leads to an improvement of thermal stability in comparison with unfilled polymers as well as nanocomposites containing only unmodified alumina. Furthermore, the surface modification of aluminum oxide nanoparticles allows the significant reduction of the peak of HRR measured by cone calorimetry in the case of PMMA nanocomposites. An improvement of fire behavior was also observed for PS nanocomposites but we noted that surface modification of alumina particles with organophosphorus compounds did not promote an additional decrease of pHRR compared to hydrophilic alumina.

Thus, this study highlighted the interest of surface modification of alumina nanoparticles to enhance thermal stability and fire behavior of nanocomposites. Such modified oxide nanoparticles would be promising candidates to use in synergy with other conventional flame retardants in order to optimize fire-retardant properties of polymers.

\section{Acknowledgements}

We would like to thank the "Service Central d'Analyses du CNRS" (Vernaison, France) for elemental analyses.

\section{REFERENCES}

[1] A. Laachachi, E. Leroy, M. Cochez, M. Ferriol, J. M. Lopez Cuesta, Polym. Degrad. Stab. 2005, 89, 344.

[2] F. Yang, G. L. Nelson, Polym. Adv. Technol. 2006, 17, 320.

[3] A. Aruchamy, K. A. Blackmore, B. J. J. Zelinski, D. R. Uhlmanm, C. Booth, Mater. Res. Soc. Symp. Proc. 1992, 249, 353.

[4] Y. H. Hu, C. Y. Chen, C. C. Wang, Polym. Degrad. Stab. 2004, 84, 545.

[5] A. Laachachi, M. Cochez, M. Ferriol, J. M. Lopez-Cuesta, E. Leroy, Mater. Lett. 2005, 59, 36.

[6] A. Laachachi, M. Ferriol, M. Cochez, D. Ruch, J. M. Lopez-Cuesta, Polym. Degrad. Stab. 2008, 93, 1131.

[7] D. Baskaran, J. W. Mays, M. S. Bratcher, Polymer 2005, 46, 5050.

[8] S. K. Parida, P. K. Mishra, B. K. Mishra, Indian J. Chem. 1999, 38A, 639.

[9] N. Cinausero, N. Azéma, M. Cochez, M. Ferriol, M. Essahli, F. Ganachaud, J. M. Lopez-Cuesta, Polym. Adv. Technol. 2008, 18, 701.

[10] G. Guerrero, H. P. Mutin, A. Vioux, J. Mater. Chem. 2001, 11, 3161.

[11] D. Lin-Vien, N. B. Colthup, W. G. Fateley, J. G. Grasselli, The Handbook of Infrared and Raman Characteristic Frequencies of Organic Molecules, Academic Press, New York.

[12] J. McElwee, R. Helmy, A. Y. Fadeev, J. Colloid Interface Sci. 2005, 285, 551.

[13] T. Kashiwagi, A. B. Morgan, J. M. Antonucci, M. R. VanLandingham, R. H. Harris, Jr., W. H. Awad, J. R. Shields, J. Appl. Polym. Sci. 2003, 89, 2072.

[14] J. R. Ebdon, D. Price, B. J. Hunt, P. Joseph, F. Gao, G. J. Milnes, L. K. Cunliffe, Polym. Degrad. Stab. 2000, 69, 267.

[15] C. I. Lindsay, S. B. Hill, M. Hearn, G. Manton, N. Everall, A. Bunn, J. Heron, I. Fletcher, Polym. Int. 2000, 49, 1183.

[16] N. Cinausero, PhD Thesis, Université des Sciences et Techniques de Montpellier, 2009, http://tel.archives-ouvertes.fr/tel-00382965/en/.

[17] J. Kuljanin, M. Marinovic-Cincovic, S. Zec, M. I. Comor, J. M. Nedeljkovic, J. Mater. Sci. Lett. 2003, 22, 235.

[18] M. Marinovic-Cincovic, Z. V. Saponjic, V. Djokovic, S. K. Milonjic, J. M. Nedeljkovic, Polym. Degrad. Stab. 2006, 91, 313.

[19] Y. Hu, S. Li, J. Anal. Appl. Pyrolysis 2007, 78, 32.

[20] B. N. Jang, C. A. Wilkie, Polymer 2005, 46, 2933. 